\title{
Pi Day: An International Festival of Mathematics
}

Elena Berardini (Aix-Marseille Université, Marseille, France), Joël Cohen (Université Paris Sud, Orsay, France), Guillaume Geoffroy (Aix-Marseille Université, Marseille, France) and Annamaria lezzi (University of South Florida, Tampa, USA)

We, as mathematicians, may not have a patron saint but we do have a favourite number: it goes by the name of " $\pi$ ", "pi", "the circle constant" or "approximately 3.14". This number is so dear to us that we have reserved a special button for it on most calculators and we have created a holiday in its honour: 14 March. This tradition comes from the United States, where this date is written 3.14 and where it was celebrated for the first time in 1988, at the Exploratorium of San Francisco.

Every year, Pi Day is an opportunity for all mathematicians, geeks and science enthusiasts around the world to get together and celebrate science, not to mention the excuse to eat pie.

Eager to get in on this pie-eating action, a group of PhD students in Marseille with a lot of enthusiasm, energy and perhaps a dash of irrationality imported the concept across the ocean. Their original idea was to blend education and entertainment together into one. What started out in 2013 as a small gathering at a PhD student seminar with pies soon became a bigger event that attracted thousands of people from the general public. Thus was born the Pi Day Association, which now travels across France showcasing its own mathematical musicals.

\section{A mathematical musical!}

Since 2015, our association has written and produced a new show every year, blending various elements of music, entertainment and education together. In 2016, we reworked the formula and combined the elements into a musical about the life and scientific discoveries of Archimedes. The show was a great success that attracted nearly 800 spectators and received the d'Alembert Prize of the French Mathematical Society. In 2017, we were back with an even bigger project: a brand new musical entitled From Marseille to Vegas. We gave three (not quite $\pi$ ) performances: one in Paris (Théâtre des Variétés) on 14 March, one in Marseille (Le Silo) on 16 March and one in Lyon (Le Transbordeur) on 19 March.

From Marseille to Vegas is a story about the misadventures of four PhD students. Having grown tired and disenchanted with academic life, they dream up the crazy idea of trying their luck at the casinos in Las Vegas using their mathematical knowledge. Can they play chance with mathematics? This musical humorously addresses the themes of probability theory, the life and status of $\mathrm{PhD}$ students and the role of mathematics and science in society.
Each performance was accompanied by three short talks given by experienced popularisers of mathematics. The speakers and their topics came from different backgrounds but they all revolved around the general theme of randomness. We learnt, among other things, how to cheat at slot machines, how to tame crowds with mathematical formulas and how Leonardo Fibonacci liked his pasta. We spent some time wondering if statistics really mean anything and if it is really such a small, small world after all.

Before the performance and during the break, members of the audience could take part in mathematical activities organised by students. The third event, in Lyon, also featured the traditional pie contest: participants were invited to bring their pies, share them with the rest of the spectators and try to win the best prizes.

\section{A successful bet for mathematics}

In total, the three events attracted almost 2,000 spectators of all ages, who came to learn, think, dream, laugh and sing to the sound of mathematics: quite a success for such a "boring" science!

In case you were unlucky enough to miss the event, you can catch up on our website: www.piday.fr. Stay tuned for our next musical, slated to premiere on March 14, 2019, and to be performed across France. If you want to support us, join us in our new project or if you would like the show to come to your city, do not hesitate to contact us! We are looking forward to meeting you for a new series of irrational, transcendental, but probably normal events!

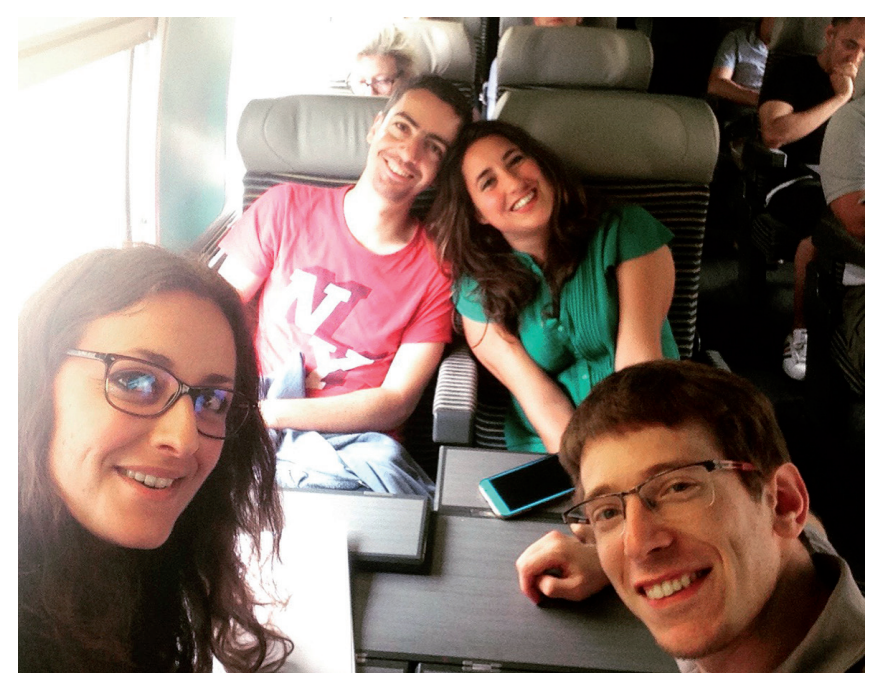


Elena Berardini is a PhD student in mathematics at AixMarseille Universite and is treasurer of the association.

Joël Cohen is a lecturer at Universite Paris-Sud and is vice-president of the association.

Guillaume Geoffroy is a PhD student in mathematics at Aix-Marseille Université and is president of the association.

Annamaria Iezzi is a postdoctoral researcher in mathematics at the University of South Florida and is secretary of the association.
Together, they organised Pi Day 2017 in Paris, Lyon and Marseille. In particular, Joël and Guillaume wrote the musical and coordinated the artistic committee, and Annamaria and Elena were in charge of coordinating the actual realisation of the project, from funding to communication and stage set.

None of this would have been possible without an extensive team of volunteers and many sponsors: the names of all the culprits are listed on www.piday.fr. 